\title{
A Network-Based Data Envelope Analysis Model in a Dynamic Balanced Score Card
}

\author{
Mojtaba Akbarian, ${ }^{1}$ Esmaeil Najafi, ${ }^{1}$ Reza Tavakkoli-Moghaddam, ${ }^{2}$ \\ and Farhad Hosseinzadeh-Lotfi ${ }^{3}$ \\ ${ }^{1}$ Department of Industrial Engineering, Islamic Azad University, Science and Research Branch, Tehran, Iran \\ ${ }^{2}$ School of Industrial Engineering, College of Engineering, University of Tehran, Tehran, Iran \\ ${ }^{3}$ Department of Mathematics, Islamic Azad University, Science and Research Branch, Tehran, Iran
}

Correspondence should be addressed to Mojtaba Akbarian; mojtabaakbaryan@gmail.com

Received 17 October 2014; Revised 20 December 2014; Accepted 2 March 2015

Academic Editor: Pandian Vasant

\begin{abstract}
Copyright ( $\odot 2015$ Mojtaba Akbarian et al. This is an open access article distributed under the Creative Commons Attribution License, which permits unrestricted use, distribution, and reproduction in any medium, provided the original work is properly cited.

Performance assessment during the time and along with strategies is the most important requirements of top managers. To assess the performance, a balanced score card (BSC) along with strategic goals and a data envelopment analysis (DEA) are used as powerful qualitative and quantitative tools, respectively. By integrating these two models, their strengths are used and their weaknesses are removed. In this paper, an integrated framework of the BSC and DEA models is proposed for measuring the efficiency during the time and along with strategies based on the time delay of the lag key performance indicators (KPIs) of the BSC model. The causal relationships during the time among perspectives of the BSC model are drawn as dynamic BSC at first. Then, after identifying the network-DEA structure, a new objective function for measuring the efficiency of nine subsidiary refineries of the National Iranian Oil Refining and Distribution Company (NIORDC) during the time and along with strategies is developed.
\end{abstract}

\section{Introduction}

Performance management is one of the most important issues, in which if the organizational vision is used, future decision making of an organization will be achieved along with strategic goals. There are a number of performance assessment tools in the literature; however, the balanced score card (BSC) is used only along with strategic goals. By implementing the BSC, organizations should translate their visions to strategic objectives, link their vision to individual performance, and measure their performance along with their visions [1].

The BSC methodology is a performance management system for today's successful organizations. It indicates the organizational mission and vision in a set of cause-and-effect relationships in four perspectives (i.e., financial, customer, internal processes and learning, and growth) [2]. The BSC innovators introduced cause-and-effect relationships based on key performance indicators (KPIs) to link strategies to vision. The chains of the cause-and-effect relation connect all the factors with performance indicators through the four perspectives of the BSC model, which reflect dynamically the change of strategies and indicate how an organization creates its value [3].

The BSC model controls the vision and strategies by performance indicators. The financial indicators are insufficient in explaining the performance because they only contain the information which has taken place in the past. Then, Kaplan and Norton introduced the BSC system, which integrates the indicators regarding the past performance with the indicators regarding the elements that will bring future performances. By using the BSC, balance between performance drivers, named lead KPIs, and outcome measures, named lag KPIs, is created. The lead KPIs communicate the way to achieve vision and indicate early whether strategies are being implemented successfully. The lag KPIs may enable organization to accomplish long-term operational improvements and enhance financial performance. The ideal BSC should have an appropriate mix of the lead KPIs and the lag KPIs tailored to the business unit's strategy [4]. 
Continuous performance assessment during the time and along with strategic goals is desirable for top managers of an organization. It is suitable for continuous control of any organization. Performance assessment in the BSC is based on lag and lead KPIs. Due to delay of lag KPIs in the BSC, relationships between four perspectives are not simple and dynamics in the BSC perspectives appeared. Despite the capability of the BSC for evaluating the performance based on KPIs, the lack of quantitative methods for measuring the performance is a major weakness. To tackle this weakness, the DEA model can be considered as one of the best mathematical methods to calculate the performance. Despite its capability for evaluating the performance, inability to determine the input and output variables is a main weakness.

The weakness of input and output variables in the DEA model is removed through KPIs of the BSC model and the lack of the quantitative method for measuring the performance is also removed through the DEA model. By integrating these BSC and DEA models, their weaknesses are removed and the synergy for the performance assessment during the time is achieved. According to the abovementioned points, integration of two performance assessment models during the time and along with strategic goals is the main purpose of this paper.

Many studies have been done on the simultaneous use of the DEA and BSC models for performance assessment. Rouse et al. [5] first studied a DEA analysis integrated with the BSC model. They used the DEA model to measure the efficiency over time and then used four perspectives of the BSC model as variables of the DEA model. Eilat et al. [6] used mixed DEA, BSC, and branch-and-bound algorithm in order to develop their previous study [7] proposing a framework for selection of the R\&D projects. Chen et al. [8] used an integrated DEA and BSC model to measure the selection of KPI results at a credit cooperative bank in Taiwan with four models. The first model includes input and output variables, the second model includes BSC indicators, the third model includes BSC risk indicators, and the fourth model includes traditional financial indicators. García-Valderrama et al. [9] and Chiang and Lin [10] developed a DEA model to compare the tradeoffs between financial and nonfinancial KPIs in the BSC by considering the KPI of the BSC model as a variable in the DEA model.

Maced et al. [11] used an integrated DEA and BSC model with six KPIs based on six BSC perspectives as variables in order to evaluate the performance of bank branches in Brazil. Asosheh et al. [12] used integrated BSC and DEA models to measure the efficiency of projects in Iran Ministry of Science, Research and Technology with the fuzzy data. Amado et al. [13] used DEA and BSC models to measure the performance of a multinational company. Most studies have used the KPIs of BSC model as input and output variables in the classic DEA model.

Because of time delay in the lag KPIs of the BSC model, considering the time factor for performance assessment is essential. To consider the time delay resulting from the lag KPIs, the dynamic cause-and-effect relation of the BSC model in different periods based on judgment of experts must be determined.
Different studies to draw causal relationships between perspectives of BSC based on judgment are done. The DEMATEL model [14-17], DEMATEL model with fuzzy data $[18,19]$, and the DEMATEL and ANP model $[20,21]$ are used to identify the causal relationships among strategic objectives. Apart from these, similar studies have been conducted on drawing cause-and-effect relationships. For example, Jeng and Tzeng [22] used the fuzzy DEMATEL model to discover the causal relationship between the important variables. Ren et al. [23] used the DEMATEL model to recognize the causeand-effect relation to improve the sustainability of a hydrogen supply chain. Horng et al. [24] used the DEMATEL model to identify the critical standard and draw the cause-and-effect relation between them for the future restaurant space design.

By revealing the cause-and-effect relation during the time of the BSC model, the classic DEA model is not suitable quantitative one to measure the efficiency. Thus, a network-based DEA model is needed. Different studies on this network model have been carried out. The reader may read more details in Kao [25]. The basic two-stage is the simplest network structure, in which all inputs from outside are supplied to the first process to produce intermediate products for the second process to produce the final outputs. Each stage is named process and total structure is named system.

Seiford and Zhu [26] measured the performance of US commercial banks by using a basic two-stage structure. Based on this work, a lot of studies have been carried out. Yang [27] used an average model to measure the process efficiencies of insurance companies in Canada. Kao and Hwang [28] proposed a relational model with a product of two processes as objective function to measure the system efficiency of nonlife insurance companies in Taiwan. Chiou et al. [29] considered the average of two processes as objective function to measure the efficiencies of bus companies in Taiwan. Chen et al. [30] used a system distance model with a weighted average approach as objective function considering projection of the intermediate variable to measure the efficiency.

Wang and Chin [31] showed that if the weight of each process is defined as the aggregate output of the process in that of two processes, then the aggregate efficiency is a weighted harmonic average of the process efficiencies. Kao and Hwang [32] used BCC input and output models for efficiency measurement of the first and second process models, respectively. Then, they decomposed the system efficiency as a product of the technical and scale efficiencies. Lewis et al. [33] minimized the input parameter and maximized the output parameter to measure the performance of Major League Baseball teams.

A general two-stage structure allows both stages to consume exogenous inputs supplied from outside. For the first time, Charnes et al. [34] used this structure for measuring the efficiency of each process treated as a decision making unit (DMU). Kao and Hwang [35] extended their previous model [28] for the general two-stage structure that the inputs were shared with the second process. Chen et al. [36] used a weighted average of the two process efficiencies as objective function. Liang et al. [37] developed two models to measure the efficiency. One model is to maximize the average of 


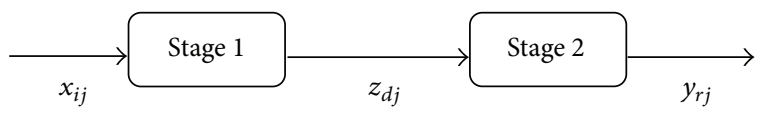

FIgURE 1: Basic two-stage structure.

the two process efficiencies, and the other model is to give a higher priority to one process. Xie et al. [38] minimized a weighted input process distance function for efficiency measurement of regions in China. Lozano et al. [39] used a distance function for measuring the performance of Spanish airports.

A series structure appeared with generalization of the general two-stage structure considering a number of processes connected in sequence, in which each process consumes the exogenous inputs and intermediate products by the preceding process. Nouri et al. [40] defined series structure with five stages for measuring the system and process efficiencies of plants in Iran. Kao and Liu [41] used multiperiod system without intermediate products for performance measurement of commercial banks in Taiwan with this structure.

Another type of the network is parallel structure that is the same as the multiperiod system; however, input or output variables can be shared. Kao [42] proposed a parallel system to measure the system and process efficiencies with the weighted average of the component process efficiencies as objective function. Bi et al. [43] proposed the parallel structure, in which the inputs were shared and the outputs were the contribution of both processes.

There are network systems whose structures are neither series nor parallel, but a mixture of them, named mixed structure. Chen and Yan [20] defined a mixed three-stage structure for performance measurement of supply chains, in which the system efficiency was the product of the process efficiency. Adler et al. [44] defined a mixed two-stage structure, in which the first and second stages had one and two processes for the performance assessment of airports in European countries, respectively. Wang et al. [45] used a mixed twostage structure, in which the first stage divides to two parallel processes and the objective function minimizes the weighted average of the input and output distance parameters of the first and second stages for efficiencies measurement of hightech firms in Taiwan, respectively. Lin and Chiu [46] defined a mixed three-stage structure, in which the second stage is composed of two parallel subprocesses for the Taiwanese domestic bank's performance assessment.

With regard to the above division of the existing network DEA models in the previous section, a basic two-stage structure of the network DEA model as basic model of this paper is described in Figure 1, where all inputs $\left(X_{i}\right)$ from outside are supplied to the first process to produce intermediate products $\left(Z_{d}\right)$ for the second process to produce the final outputs $\left(Y_{r}\right)$.

Chen et al. [30] proposed a weighted additive with the arithmetic mean approach named additive model.
Components of a two-stage process and proposed overall efficiency of the two-stage process are given by

$$
w_{1} \cdot \frac{\sum_{d=1}^{D} \gamma_{d} z_{d p}}{\sum_{i=1}^{m} v_{i} x_{i p}}+w_{2} \cdot \frac{\sum_{r=1}^{s} u_{r} y_{r p}}{\sum_{d=1}^{D} \gamma_{d} z_{d p}},
$$

where $w_{1}+w_{2}=1$. These weights are not decision variables, but rather are functions of decision variables. By setting for stage $p$ of $\mathrm{DMU}_{p}, w_{p}$ is the proportion of the total resources for the process that are devoted to stage $p$, reflecting the relative size of that stage as follows:

$$
w_{p}=\frac{\text { (component } p \text { input) }}{\text { (total input accross all components) }} .
$$

Then, for the basic two-stage structure, we have

$$
\begin{aligned}
& w_{1}=\frac{\sum_{i=1}^{m} v_{i} x_{i p}}{\sum_{i=1}^{m} v_{i} x_{i p}+\sum_{d=1}^{D} \gamma_{d} z_{d p}} \\
& w_{2}=\frac{\sum_{d=1}^{D} \gamma_{d} z_{d p}}{\sum_{i=1}^{m} v_{i} x_{i p}+\sum_{d=1}^{D} \gamma_{d} z_{d p}} .
\end{aligned}
$$

The overall efficiency of the process is calculated by solving the following nonlinear problem, named additive model as follows:

$$
\begin{gathered}
\max z=w_{1} \cdot \frac{\sum_{d=1}^{D} \gamma_{d} z_{d p}}{\sum_{i=1}^{m} v_{i} x_{i p}}+w_{2} \cdot \frac{\sum_{r=1}^{s} u_{r} y_{r p}}{\sum_{d=1}^{D} \gamma_{d} z_{d p}} \\
\frac{\sum_{d=1}^{D} \gamma_{d} z_{d j}}{\sum_{i=1}^{m} v_{i} x_{i j}} \leq 1 \\
\frac{\sum_{r=1}^{s} u_{r} y_{r j}}{\sum_{d=1}^{D} \gamma_{d} z_{d j}} \leq 1 \\
\gamma_{d}, v_{i}, u_{r} \geq 0, \quad j=1,2, \ldots, n .
\end{gathered}
$$

In this paper, based on this basic structure of network-DEA, a new model for efficiency measurement is developed.

By considering a time factor resulting from the lag KPIs of the BSC model, the time series analysis can be used. Klepac introduced the REFII model to automate the time series analysis, through a unique transformation model of time series in 2005. It is an authorial mathematical model for time series data mining. Furthermore, he used it to evaluate risk in an insurance company [47].

\section{Materials and Methods}

2.1. Proposed Framework. Deployment of the BSC model is not the purpose of this paper; however, efficiency measurement during the time and along with strategic goals integrating of the BSC and DEA models is the main purpose of this paper. By the simultaneous use of these two models, the purpose of this paper is followed. Despite various studies on the simultaneous use of the BSC and DEA models, almost 
all studies used KPIs of the BSC model as input and output variables in the classic DEA model. These studies did not consider a dynamic factor resulting from the delay of the lag KPIs as dynamic variables with severance of the lead and lag KPIs.

To consider the time factor, in addition to identifying causal relationships of the BSC perspectives at a time period, dynamic causal relationships of BSC perspectives at different periods should also be considered.

After dividing the KPIs into four perspectives of the BSC model and identifying the lead and lag KPIs, dynamic and nondynamic relationships between perspectives of the BSC resulting from lag and lead KPIs are determined based on expert judgment, respectively.

Several studies have been carried out to draw the causeand-effect relations among perspectives of the BSC model with expert judgment. However, none of them has considered delay of the lag KPIs. In the first stage of the proposed framework, the dynamic and nondynamic cause-and-effect relations considering the lag and lead KPIs between perspectives of the BSC model are drawn with fuzzy DEMATEL model, respectively. For identifying dynamic causal relationships, the relation matrix between perspectives of BSC with attention to the lead and lag KPIs are created in a dynamic pattern as shown in Figure 3. The relationships in the perspectives of the same period and between perspectives of different periods are shown in gray and white cells, respectively. This matrix is created by using expert judgment and considering relationship of the lag and lead KPIs. The linguistic variables are used to decrease obscurity of expert judgment.

In the second stage of the proposed framework, fuzzy DEMATEL model is used to determine the dynamic and nondynamic cause-and-effect relations between perspectives of different and same periods, respectively. Then, after defuzzification of fuzzy DEMATEL calculation, dynamic cause-and-effect relations between perspectives in different periods are drawn as dynamic BSC.

The BSC model evaluates the efficiency along with strategy. Hence, for measuring the efficiency along with a strategy and during the time, a DEA mathematical method should be added to the dynamic BSC. Then, after identifying causal networks of BSC perspectives, a classic DEA model is not suitable. Thus, a network-DEA model is required. Despite several studies have been done on the network DEA as reviewed in the previous section, none of them has not considered network relations of the third level. In the third stage of the proposed framework considering third level, a new network DEA structure for measuring the efficiency is introduced. Then, dynamic and nondynamic variables resulting from the lag and lead KPIs are defined as variables, respectively.

Chen et al. [30] used the weighted additive with the arithmetic mean approach of the second level. However, by defining the third level in the proposed network DEA structure, a new objective function is defined. Then, modeling for optimization of the proposed structure is done. Finally, in the sixth stage, the efficiency of decision making units based on the data set of the KPIs of BSC model as variables is measured. By deploying this proposed framework,

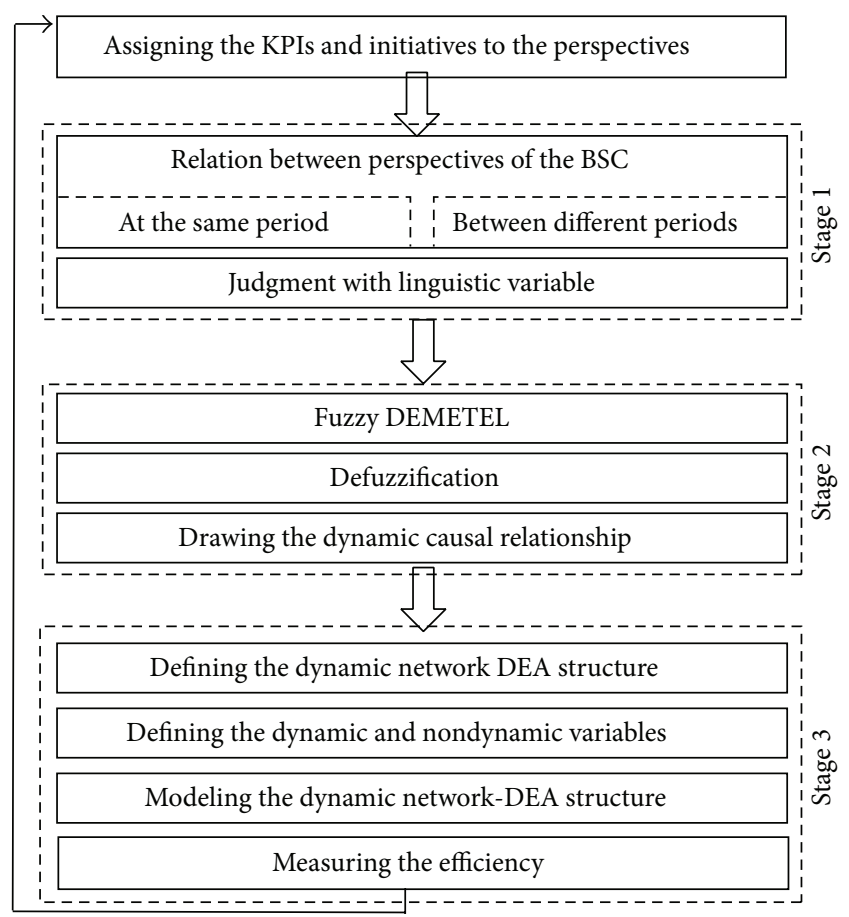

FIGURE 2: Proposed framework.

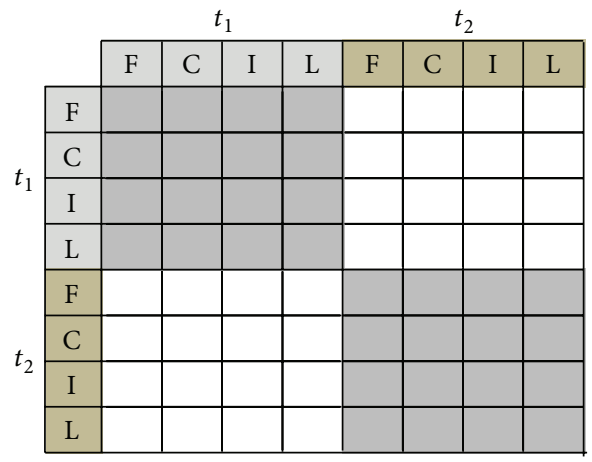

FIgURE 3: Dynamic relation matrix.

the efficiency of DMUs during the times and along with strategic goals is measured. After identifying the efficiency of DMUs, the strategic initiatives are redefined to improve the efficiency scores with feedback lines as shown in Figure 2.

2.2. Case Analysis. The National Iranian Oil Refining and Distribution Company (NIORDC) was established on the principle of separating upstream activities, which has nine oil existing refineries. These companies have performed National Iranian Oil Company's activities in the area of all activities related to crude oil transportation to the refineries and export jetties, processing, production and distribution of numerous oil main products and byproducts throughout Iran, marketing and exporting special products surplus, construction of refineries, marine platforms, pipelines, and communication networks, and ensuring internal and long 
TABLE 1: KPIs of the BSC model.

\begin{tabular}{lccc}
\hline Perspectives & Key performance indicators & Type & Strategic initiative \\
\hline \multirow{2}{*}{ Financial } & Net profit margin & Lead & Productivity cycle project \\
& Annual budget & Activity based costing \\
& Strategic plans & Lag & Strategic thinking for managers \\
\hline \multirow{2}{*}{ Customer } & Increase of refinery capacity & Lag & ISO 10004 \\
& Quality of oil products & Lead & ISO 10002 \\
\hline \multirow{2}{*}{ Internal process } & Material assigned to refinery & Lead & Total maintenance management \\
& Gas production in the refinery & Lead & ISO TS29001 \\
& Safety stock for refinery & Lead & Outsourcing management \\
& Outsourcing & Lag & ISO 10015 \\
Learning and growth & Training & Lead & Lag \\
& Effectiveness of training & Lead & Lag
\end{tabular}

distance, industrial and official headquarters of Oil Ministry communication with the extreme capability.

In this paper, the efficiency of nine oil existing refineries of the NIORDC is measured as case analysis. The KPIs of the NIORDC is divided into four perspectives of the BSC model based on oil expert comments in Table 1. The strategic initiatives are also assigned to perspectives for improving them. The result of the lag KPIs occurs with time delay because they introduce the past performance. The lead KPIs do not occur with time delay because they introduce elements that will bring future performances. The lead and lag KPIs identified in the Table 1 help oil experts to have judgment. For improving the perspectives, the strategic initiatives are defined for them.

2.2.1. Relation between Perspectives of the BSC. In this stage, a dynamic relation matrix with attention to the lead and lag KPIs between perspectives of a period and different periods is identified, respectively. The lag KPIs occurs with delay. For this reason, the cause-and-effect relations between perspectives in different periods of the BSC model are created with delay. The lead KPIs do not have delay and create a nondynamic cause-and-effect relations between perspectives at the same period without any delay.

According to the pattern presented in Figure 3, three groups of oil experts judge the relationship of the BSC perspectives in different and the same periods with attention to the lag and lead KPIs with linguistic variables, respectively. To ensure a correct judgment of oil experts, the result of the lead and lag KPIs corresponding to the BSC perspectives is presented for them. Then with awareness of the NIORDC lead and lag KPIs, the relationship between the perspectives is judged. Due to space limitations, description of the lead and lag KPIs is ignored. Linguistic judgment of the first oil expert group on a dynamic relation matrix is shown in Table 2 . The perspectives of the BSC model are presented as financial $(\mathrm{F})$, customer (C), internal processes (I), and learning and growth (L).

2.2.2. Drawing the Dynamic Causal Relationship. By adopting a fuzzy triangular number and linguistic values as shown in Table 3, a fuzzy DEMATEL model is used by expressing
TABLE 2: Dynamic linguistic assessment of oil experts.

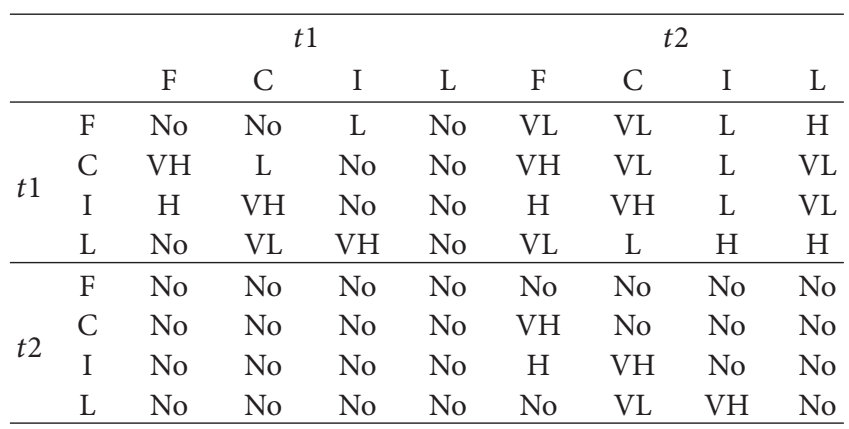

TABLE 3: Linguistic values and corresponding terms.

\begin{tabular}{lc}
\hline Linguistic terms & Linguistic value \\
\hline Very high influence $(\mathrm{VH})$ & $(0.75,1,1)$ \\
High influence $(\mathrm{H})$ & $(0.5,0.75,1)$ \\
Low influence $(\mathrm{L})$ & $(0.25,0.5,0.75)$ \\
Very low influence (VL) & $(0,0.25,0.5)$ \\
No influence (No) & $(0,0,0.25)$ \\
\hline
\end{tabular}

different degrees of influences or causalities with five linguistic terms as \{Very high, High, Low, Very low, No\} and their corresponding triangular fuzzy numbers [48].

Suppose $\check{Z}_{\tilde{p}}=\left(l_{i j}^{n}, m_{i j}^{n}, u_{i j}^{n}\right)$ are triangular fuzzy numbers and are obtained from assessment of oil experts. The average of these assessments is accounted by using the following equation as shown in Table 4, which is called a dynamic relation fuzzy matrix:

$$
\widetilde{Z}=\frac{\widetilde{z_{1}} \oplus \widetilde{z_{2}} \cdots \oplus \widetilde{z_{p}}}{P} .
$$

By normalizing a dynamic relation fuzzy matrix, a normalized dynamic relation fuzzy matrix $(\widetilde{X})$ is calculated by

$$
\begin{gathered}
\widetilde{x}_{i j}=\frac{\widetilde{Z}_{i j}}{r}=\left[\frac{\tilde{l}_{i j}}{r}, \frac{\widetilde{m}_{i j}}{r}, \frac{\widetilde{u}_{i j}}{r}\right] \\
r=\max _{1 \leq i \leq n}\left(\sum_{j=1}^{n} U_{i j}\right) .
\end{gathered}
$$


TABLE 4: Dynamic relation fuzzy matrix.

\begin{tabular}{|c|c|c|c|c|c|c|c|c|c|c|c|c|c|c|c|c|c|c|c|c|c|c|c|c|}
\hline & \multicolumn{3}{|c|}{$\mathrm{F} 1$} & \multicolumn{3}{|c|}{$\mathrm{C} 1$} & \multicolumn{3}{|c|}{ I1 } & \multicolumn{3}{|c|}{ L1 } & \multicolumn{3}{|c|}{ F2 } & \multicolumn{3}{|c|}{$\mathrm{C} 2$} & \multicolumn{3}{|c|}{$\mathrm{I} 2$} & \multicolumn{3}{|c|}{ L2 } \\
\hline & $\mathrm{L}$ & $\mathrm{M}$ & $\mathrm{U}$ & $\mathrm{L}$ & $\mathrm{M}$ & $\mathrm{U}$ & $\mathrm{L}$ & $\mathrm{M}$ & $\mathrm{U}$ & $\mathrm{L}$ & M & $\mathrm{U}$ & $\mathrm{L}$ & $\mathrm{M}$ & $\mathrm{U}$ & $\mathrm{L}$ & $\mathrm{M}$ & $\mathrm{U}$ & $\mathrm{L}$ & $\mathrm{M}$ & $\mathrm{U}$ & $\mathrm{L}$ & $\mathrm{M}$ & $\mathrm{U}$ \\
\hline $\mathrm{F} 1$ & 0 & 0 & 0.3 & 0 & 0 & 0.3 & 0.3 & 0.4 & 0.7 & 0 & 0 & 0.3 & 0 & 0.3 & 0.5 & 0 & 0.3 & 0.5 & 0.5 & 0.8 & 0.9 & 0.5 & 0.8 & 1 \\
\hline $\mathrm{Cl}$ & 0.8 & 1 & 1 & 0 & 0 & 0.3 & 0 & 0 & 0.3 & 0 & 0 & 0.3 & 0.8 & 1 & 1 & 0 & 0.3 & 0.5 & 0.2 & 0.4 & 0.7 & 0 & 0.3 & 0.5 \\
\hline I1 & 0.5 & 0.8 & 1 & 0.8 & 1 & 1 & 0.2 & 0.3 & 0.6 & 0 & 0 & 0.3 & 0.5 & 0.8 & 1 & 0.8 & 1 & 1 & 0.3 & 0.6 & 0.8 & 0.1 & 0.3 & 0.6 \\
\hline L1 & 0.1 & 0.2 & 0.4 & 0.1 & 0.3 & 0.6 & 0.8 & 1 & 1 & 0 & 0.1 & 0.3 & 0.3 & 0.5 & 0.7 & 0.3 & 0.5 & 0.8 & 0.7 & 0.9 & 1 & 0.5 & 0.8 & 1 \\
\hline $\mathrm{F} 2$ & 0 & 0 & 0.3 & 0 & 0 & 0.3 & 0 & 0 & 0.3 & 0 & 0 & 0.3 & 0 & 0 & 0.3 & 0 & 0 & 0.3 & 0.3 & 0.4 & 0.7 & 0 & 0 & 0.3 \\
\hline $\mathrm{C} 2$ & 0 & 0 & 0.3 & 0 & 0 & 0.3 & 0 & 0 & 0.3 & 0 & 0 & 0.3 & 0.8 & 1 & 1 & 0 & 0 & 0.3 & 0 & 0 & 0.3 & 0 & 0 & 0.3 \\
\hline I2 & 0 & 0 & 0.3 & 0 & 0 & 0.3 & 0 & 0 & 0.3 & 0 & 0 & 0.3 & 0.5 & 0.8 & 1 & 0.8 & 1 & 1 & 0.2 & 0.3 & 0.6 & 0 & 0 & 0.3 \\
\hline L2 & 0 & 0 & 0.3 & 0 & 0 & 0.3 & 0 & 0 & 0.3 & 0 & 0 & 0.3 & 0.1 & 0.2 & 0.4 & 0.1 & 0.3 & 0.6 & 0.8 & 1 & 1 & 0 & 0.1 & 0.3 \\
\hline
\end{tabular}

TABLE 5: Fuzzy normalized dynamic relation matrix.

\begin{tabular}{|c|c|c|c|c|c|c|c|c|c|c|c|c|c|c|c|c|c|c|c|c|c|c|c|c|}
\hline & \multicolumn{3}{|c|}{$\mathrm{F} 1$} & \multicolumn{3}{|c|}{$\mathrm{Cl}$} & \multicolumn{3}{|c|}{ I1 } & \multicolumn{3}{|c|}{ L1 } & \multicolumn{3}{|c|}{ F2 } & \multicolumn{3}{|c|}{$\mathrm{C} 2$} & \multicolumn{3}{|c|}{ I2 } & \multicolumn{3}{|c|}{ L2 } \\
\hline & $\mathrm{L}$ & $\mathrm{M}$ & $\mathrm{U}$ & $\mathrm{L}$ & $\mathrm{M}$ & $\mathrm{U}$ & $\mathrm{L}$ & $\mathrm{M}$ & $\mathrm{U}$ & $\mathrm{L}$ & $\mathrm{M}$ & $\mathrm{U}$ & $\mathrm{L}$ & $\mathrm{M}$ & $\mathrm{U}$ & $\mathrm{L}$ & $\mathrm{M}$ & $\mathrm{U}$ & $\mathrm{L}$ & $\mathrm{M}$ & $\mathrm{U}$ & $\mathrm{L}$ & $\mathrm{M}$ & $\mathrm{U}$ \\
\hline $\mathrm{F} 1$ & 0 & 0 & 0 & 0 & 0 & 0 & 0 & 0.1 & 0.1 & 0 & 0 & 0 & 0 & 0 & 0.1 & 0 & 0 & 0.1 & 0.1 & 0.1 & 0.1 & 0.1 & 0.1 & 0.2 \\
\hline $\mathrm{Cl}$ & 0.1 & 0.2 & 0.2 & 0 & 0 & 0 & 0 & 0 & 0 & 0 & 0 & 0 & 0.1 & 0.2 & 0.2 & 0 & 0 & 0.1 & 0 & 0.1 & 0.1 & 0 & 0 & 0.1 \\
\hline I1 & 0.1 & 0.1 & 0.2 & 0.1 & 0.2 & 0.2 & 0 & 0.1 & 0.1 & 0 & 0 & 0 & 0.1 & 0.1 & 0.2 & 0.1 & 0.2 & 0.2 & 0.1 & 0.1 & 0.1 & 0 & 0.1 & 0.1 \\
\hline L1 & 0 & 0 & 0.1 & 0 & 0.1 & 0.1 & 0.1 & 0.2 & 0.2 & 0 & 0 & 0.1 & 0 & 0.1 & 0.1 & 0 & 0.1 & 0.1 & 0.1 & 0.1 & 0.2 & 0.1 & 0.1 & 0.2 \\
\hline $\mathrm{F} 2$ & 0 & 0 & 0 & 0 & 0 & 0 & 0 & 0 & 0 & 0 & 0 & 0 & 0 & 0 & 0 & 0 & 0 & 0 & 0 & 0.1 & 0.1 & 0 & 0 & 0 \\
\hline $\mathrm{C} 2$ & 0 & 0 & 0 & 0 & 0 & 0 & 0 & 0 & 0 & 0 & 0 & 0 & 0.1 & 0.2 & 0.2 & 0 & 0 & 0 & 0 & 0 & 0 & 0 & 0 & 0 \\
\hline I2 & 0 & 0 & 0 & 0 & 0 & 0 & 0 & 0 & 0 & 0 & 0 & 0 & 0.1 & 0.1 & 0.2 & 0.1 & 0.2 & 0.2 & 0 & 0.1 & 0.1 & 0 & 0 & 0 \\
\hline L2 & 0 & 0 & 0 & 0 & 0 & 0 & 0 & 0 & 0 & 0 & 0 & 0 & 0 & 0 & 0.1 & 0 & 0.1 & 0.1 & 0.1 & 0.2 & 0.2 & 0 & 0 & 0.1 \\
\hline
\end{tabular}

It is assumed that at least one $i$ exists such that $\sum_{j=1}^{n} U_{i j}<1$ [48]. According to Table 4 and considering the mean of a fuzzy relation matrix and judgment of oil experts, 6.25 for $r$-value is defined. The fuzzy normalized dynamic relation matrix is illustrated in Tables 4 and 5. Next, the total fuzzy relation matrix is calculated by using (7) and the total dynamic fuzzy relation matrix is illustrated in Table 6:

$$
\begin{aligned}
& \widetilde{T}=\lim _{k \rightarrow \infty}\left(\widetilde{X}^{1}+\widetilde{X}^{2}+\cdots \widetilde{X}^{k}\right)^{n} \\
& \widetilde{T}=\left[\begin{array}{ccc}
\widetilde{t}_{11} & \cdots & \tilde{t}_{1 n} \\
\vdots & \ddots & \vdots \\
\tilde{t}_{n 1} & \cdots & \tilde{t}_{n n}
\end{array}\right], \quad \widetilde{t}_{i j}=\left(l_{i j}^{\prime \prime}, m_{i j}^{\prime \prime}, u_{i j}^{\prime \prime}\right) \\
& {\left[l_{i j}^{\prime \prime}\right]=X_{l} *\left(I-X_{l}\right)^{-1}} \\
& {\left[m_{i j}^{\prime \prime}\right]=X_{m} *\left(I-X_{m}\right)^{-1}} \\
& {\left[u_{i j}^{\prime \prime}\right]=X_{u} *\left(I-X_{u}\right)^{-1} \text {. }}
\end{aligned}
$$

By producing the total dynamic fuzzy relation matrix, $\widetilde{D}_{i}+\widetilde{R}_{i}$ and $\widetilde{D}_{i}-\widetilde{R}_{i}$ are calculated, where $\widetilde{R}_{i}$ and $\widetilde{D}_{i}$ are the sum of rows and columns, respectively. To access the casual dynamic relationships between perspectives, $\widetilde{D}_{i}+\widetilde{R}_{i}$ and $\widetilde{D}_{i}-\widetilde{R}_{i}$ are calculated in our partial results in Table 6 . To finalize the procedure, all calculated $\widetilde{D}_{i}+\widetilde{R}_{i}$ and $\widetilde{D}_{i}-\widetilde{R}_{i}$ and total dynamic fuzzy relation matrix are defuzzified through simple equation (8) as shown in Tables 7 and 8:

$$
\operatorname{Crisp}(\widetilde{T})=\frac{(l+2 m+u)}{4} .
$$

After it becomes clear that how perspectives of BSC impact each other during the time, identification of threshold to remove the minor impact is essential. This threshold is determined by using expert opinion and in some cases by mean of the total relation matrix elements [49].

In this paper, after getting out by the mean of the total relation matrix elements of Table 8 as a mental assistance to oil experts, the threshold value of 0.45 based on oil experts' consensus is considered. The elements that have relationship more than 0.45 are considered to be drawn as causal relationship. By considering dynamic cause-andeffect relations between four perspectives of the BSC model, network relationships are identified as dynamic BSC depicted in Figure 4.

2.2.3. Defining the Dynamic Network DEA Structure. According to the dynamic cause-and-effect relations of perspectives as shown in Figure 4, a dynamic network-DEA structure with dynamic and nondynamic variables for one DMU is depicted in Figure 5. According to this structure, efficiencies are measured in three levels. In the first level, named system, the overall efficiency is measured. In the second level, named process, the efficiency of each period is measured. In the third level, named activity, the efficiency of each perspective in a period is measured. The dynamic and nondynamic relations 
TABLE 6: Total dynamic fuzzy relation matrix.

\begin{tabular}{|c|c|c|c|c|c|c|c|c|c|c|c|c|c|c|c|c|c|c|c|c|c|c|c|c|}
\hline & & $\mathrm{F} 1$ & & & $\mathrm{C} 1$ & & & I1 & & & L1 & & & $\mathrm{F} 2$ & & & $\mathrm{C} 2$ & & & I2 & & & L2 & \\
\hline & $\mathrm{L}$ & $\mathrm{M}$ & $\mathrm{U}$ & $\mathrm{L}$ & $\mathrm{M}$ & $\mathrm{U}$ & $\mathrm{L}$ & $\mathrm{M}$ & $\mathrm{U}$ & L1 & $\mathrm{M}$ & $\mathrm{U}$ & $\mathrm{L}$ & $\mathrm{M}$ & $\mathrm{U}$ & $\mathrm{L}$ & $\mathrm{M}$ & $\mathrm{U}$ & $\mathrm{L}$ & $\mathrm{M}$ & $\mathrm{U}$ & $\mathrm{L}$ & $\mathrm{M}$ & $\mathrm{U}$ \\
\hline $\mathrm{F} 1$ & 0 & 0 & 0 & 0 & 0 & 0 & 0 & 0. & 0.1 & 0 & 0 & 0 & 0 & 0 & 0 & 0 & 0 & 0.1 & 0.1 & 0.1 & 2 & 0.1 & 0.1 & 0.2 \\
\hline $\mathrm{C} 1$ & 0.1 & 0.2 & 0.2 & 0 & 0 & 0 & 0 & 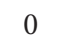 & 0 & 0 & 0 & 0 & 0.1 & 0.2 & 0.2 & 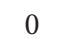 & 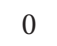 & 0.1 & o & 0.1 & 0.1 & 0 & 0 & 0.1 \\
\hline$[1$ & 0.1 & 0.1 & 0.2 & 0.1 & 0.2 & 0.2 & 0 & 0.1 & 0.1 & 0 & 0 & 0 & 0.1 & 0.1 & 0.2 & 0.1 & 0.2 & 0.2 & 0.1 & 0.1 & 0.2 & 0 & 0.1 & 0.1 \\
\hline L1 & 0 & 0 & 0.1 & 0 & 0.1 & 0.1 & 0.1 & 0.2 & 0.2 & 0 & 0 & 0.1 & 0 & 0.1 & 0.1 & 0 & 0.1 & 0.1 & 0.1 & 0.2 & 0.2 & 0.1 & 0.1 & 0.2 \\
\hline $\mathrm{F} 2$ & 0 & 0 & 0 & 0 & 0 & 0 & 0 & 0 & 0 & 0 & 0 & 0 & 0 & 0 & 0 & 0 & 0 & 0 & 0 & 0.1 & 0.1 & 0 & 0 & 0 \\
\hline $\mathrm{C} 2$ & 0 & 0 & 0 & 0 & 0 & 0 & 0 & 0 & 0 & 0 & 0 & 0 & 0.1 & 0.2 & 0.2 & 0 & 0 & 0 & 0 & 0 & 0 & 0 & 0 & 0 \\
\hline I2 & 0 & 0 & 0 & 0 & 0 & 0 & 0 & 0 & 0 & 0 & 0 & 0 & 0.1 & 0.1 & 0.2 & 0.1 & 0.2 & 0.2 & 0 & 0.1 & 0.1 & 0 & 0 & 0 \\
\hline L2 & 0 & 0 & 0 & 0 & 0 & 0 & 0 & 0 & 0 & 0 & 0 & 0 & 0 & 0 & 0.1 & 0 & 0.1 & 0.1 & 0.1 & 0.2 & 0.2 & 0 & 0 & 0.1 \\
\hline
\end{tabular}

TABLE 7: Calculation for dynamic relationships between perspectives.

\begin{tabular}{|c|c|c|c|c|c|c|c|c|c|c|c|c|c|c|}
\hline & \multicolumn{3}{|c|}{$\widetilde{D}_{i}$} & \multicolumn{3}{|c|}{$\widetilde{R}$} & \multicolumn{3}{|c|}{$\widetilde{D}_{i}-\widetilde{R}$} & \multicolumn{3}{|c|}{$\widetilde{D}_{i}+\widetilde{R}_{i}$} & \multirow{2}{*}{$D+R$} & \multirow{2}{*}{$D-R$} \\
\hline & $\mathrm{L}$ & $\mathrm{M}$ & $\mathrm{U}$ & $\mathrm{L} 1$ & $\mathrm{M}$ & $\mathrm{U}$ & $\mathrm{L}$ & $\mathrm{M}$ & $\mathrm{U}$ & $\mathrm{L}$ & $\mathrm{M}$ & $\mathrm{U}$ & & \\
\hline $\mathrm{F} 1$ & 0.2 & 0.4 & 0.8 & 0.2 & 0.4 & 0.7 & -0 & 0.1 & 0.1 & 0.5 & 0.4 & 1.4 & 0.90094 & 0.39171 \\
\hline $\mathrm{C} 1$ & 0.3 & 0.5 & 0.8 & 0.1 & 0.2 & 0.5 & 0.2 & 0.3 & 0.3 & 0.5 & 0.5 & 1.3 & 0.98389 & 1.5617 \\
\hline I1 & 0.5 & 0.9 & 1.2 & 0.2 & 0.3 & 0.6 & 0.3 & 0.6 & 0.5 & 0.7 & 0.9 & 1.8 & 1.50274 & 3.08482 \\
\hline L1 & 0.5 & 0.8 & 1.1 & 0 & 0 & 0.3 & 0.5 & 0.8 & 0.7 & 0.5 & 0.8 & 1.4 & 1.23462 & 4.18843 \\
\hline $\mathrm{F} 2$ & 0 & 0.1 & 0.4 & 0.5 & 0.8 & 1.1 & -0 & -1 & -1 & 0.5 & 0.1 & 1.5 & 0.58041 & -4.0835 \\
\hline $\mathrm{C} 2$ & 0.1 & 0.2 & 0.5 & 0.3 & 0.6 & 0.9 & -0 & -0 & -0 & 0.5 & 0.2 & 1.4 & 0.64646 & -2.2553 \\
\hline $\mathrm{I} 2$ & 0.3 & 0.4 & 0.7 & 0.5 & 0.8 & 1.1 & -0 & -0 & -0 & 0.7 & 0.4 & 1.8 & 1.01532 & -2.3134 \\
\hline L2 & 0.2 & 0.3 & 0.6 & 0.2 & 0.4 & 0.8 & -0 & -0 & -0 & 0.4 & 0.3 & 1.3 & 0.71044 & -0.5745 \\
\hline
\end{tabular}

TABLE 8: Total dynamic relation matrix.

\begin{tabular}{lcccccrrr}
\hline & F1 & C1 & I1 & L1 & F2 & C2 & I2 \\
\hline F1 & 0.042 & 0.042 & 0.447 & 0.042 & 0.254 & 0.254 & 0.804 & 0.823 \\
C1 & 1.089 & 0.042 & 0.042 & 0.042 & 1.089 & 0.254 & 0.433 \\
I1 & 0.823 & 1.089 & 0.356 & 0.042 & 0.823 & 1.089 & 0.622 \\
L1 & 0.195 & 0.342 & 1.089 & 0.11 & 0.509 & 0.526 & 0.997 & 0.342 \\
F2 & 0.042 & 0.042 & 0.042 & 0.042 & 0.042 & 0.042 & 0.447 \\
C2 & 0.042 & 0.042 & 0.042 & 0.042 & 1.089 & 0.042 & 0.042 \\
I2 & 0.042 & 0.042 & 0.042 & 0.042 & 0.823 & 1.089 & 0.356 & 0.042 \\
L2 & 0.042 & 0.042 & 0.042 & 0.042 & 0.195 & 0.342 & 0.042 \\
\hline
\end{tabular}

shown as dash and continuous lines in the dynamic networkDEA structure are the lag and lead KPIs of the BSC model, respectively.

By attention to dynamic network structure as shown in Figure 5, the first level is similar to the basic two-stage structure. It measures the overall efficiency. The external relations of perspectives among different periods are identified as dynamic relation in the second level. It is similar to general two-stage structure because it allows both processes to consume exogenous inputs and outputs from outside. The internal relations between perspectives in each period are shown in third level. It is similar to the mixed structure because of being connected by both series and parallel network relations.

2.2.4. Defining the Dynamic and Nondynamic Variables. The dynamic and nondynamic relations shown as dash and

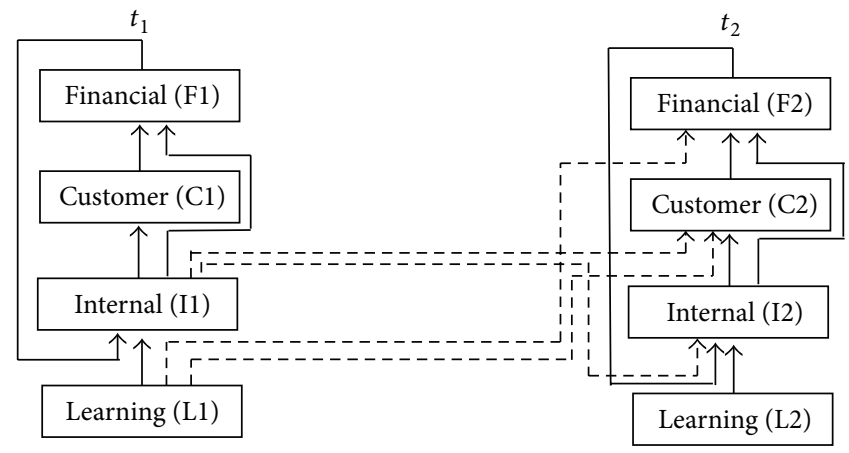

FIGURE 4: Cause-and-effect relations in the dynamic BSC.

continuous lines are the lag and lead KPIs of the BSC model, respectively. Then, the data set of nine refineries KPIs as the DMU of the NOIRDC are illustrated in Table 9. 


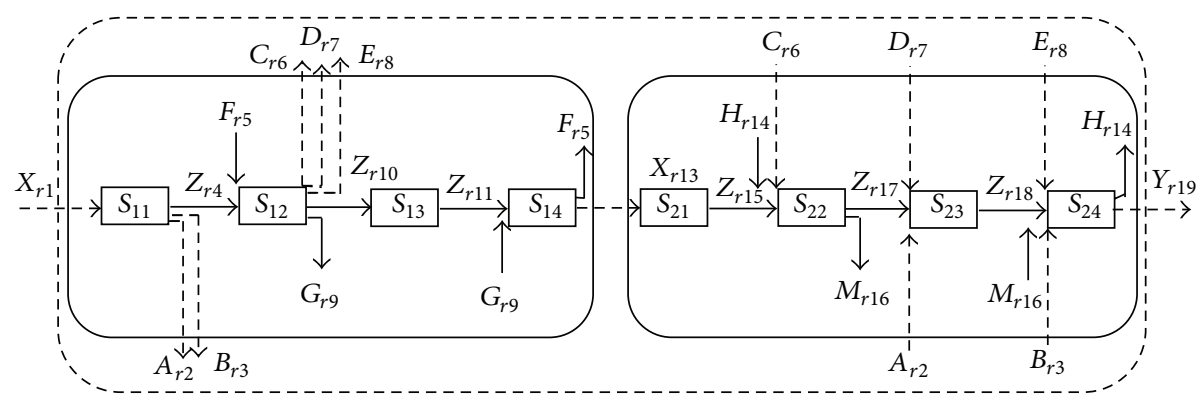

FIGURE 5: Dynamic network-DEA structure in the NIORDC.

TABLE 9: Data set of the NIORDC.

\begin{tabular}{|c|c|c|c|c|c|c|c|c|c|c|}
\hline Key performance indicators & Variables & DMU1 & DMU2 & DMU3 & DMU4 & DMU5 & DMU6 & DMU7 & DMU8 & DMU9 \\
\hline Annual budget & $\mathrm{Xr1}$ & 94 & 99 & 58 & 78 & 98 & 99 & 74 & 70 & 92 \\
\hline Customers portal changes & Ar2 & 100 & 100 & 100 & 68 & 91 & 30 & 40 & 30 & 85 \\
\hline $\begin{array}{l}\text { Effective measuring of } \\
\text { training }\end{array}$ & $\mathrm{Br} 3$ & 90 & 88 & 83 & 68 & 90 & 31 & 42 & 29 & 80 \\
\hline Training in first period & $\mathrm{Zr} 4$ & 97 & 92 & 97 & 93 & 97 & 92 & 89 & 91 & 99 \\
\hline $\begin{array}{l}\text { Management systems in } \\
\text { first period }\end{array}$ & Fr5 & 73 & 40 & 47 & 87 & 53 & 80 & 40 & 40 & 53 \\
\hline Increase refinery capacity & Cr6 & 94 & 99 & 58 & 78 & 98 & 99 & 74 & 70 & 92 \\
\hline Strategic plans & Dr7 & 100 & 100 & 100 & 68 & 91 & 30 & 40 & 30 & 85 \\
\hline Outsourcing & Er8 & 90 & 88 & 83 & 68 & 90 & 31 & 42 & 29 & 80 \\
\hline $\begin{array}{l}\text { Material assigned to } \\
\text { refinery in first period }\end{array}$ & Gr9 & 90 & 20 & 156 & 20 & 98 & 5 & 8 & 8 & 9 \\
\hline $\begin{array}{l}\text { Gas production in the } \\
\text { refinery in first period }\end{array}$ & Zr10 & 75 & 59 & 15 & 89 & 95 & 167 & 42 & 220 & 127 \\
\hline $\begin{array}{l}\text { Quality of oil products in } \\
\text { first period }\end{array}$ & Zr11 & 98 & 94 & 90 & 93 & 90 & 95 & 89 & 87 & 83 \\
\hline Safety stock for refinery & Xr13 & 54 & 44 & 20 & 72 & 44 & 35 & 76 & 46 & 20 \\
\hline $\begin{array}{l}\text { Management systems in } \\
\text { second period }\end{array}$ & Hr14 & 83 & 44 & 49 & 90 & 60 & 85 & 43 & 44 & 56 \\
\hline Training in second period & Zr15 & 100 & 100 & 100 & 68 & 91 & 96 & 98 & 79 & 98 \\
\hline $\begin{array}{l}\text { Material assigned to } \\
\text { refinery in second period }\end{array}$ & Mr16 & 93 & 24 & 165 & 26 & 102 & 10 & 13 & 11 & 12 \\
\hline $\begin{array}{l}\text { Gas production in refinery } \\
\text { in second period }\end{array}$ & Zr17 & 77 & 63 & 18 & 90 & 97 & 180 & 47 & 233 & 130 \\
\hline $\begin{array}{l}\text { Quality of oil products in } \\
\text { second period }\end{array}$ & Zr18 & 100 & 96 & 92 & 97 & 93 & 97 & 92 & 89 & 91 \\
\hline Net profit margin & Yr19 & 4.4 & 6.11 & 8.76 & 6.77 & 5.9 & 9.35 & 1 & 1 & 9.4 \\
\hline
\end{tabular}

2.2.5. Modeling the Dynamic Network-DEA Structure. The activities in the third level are perspectives of the BSC model. Based on Chen et al. [30], the efficiency of each activity is measured as follows.

For activities of Process 1,

$$
\begin{aligned}
\theta_{11}(j)= & \frac{W_{r 4} \cdot Z_{r 4 j}+W_{r 2} \cdot A_{r 2 j}+W_{r 3} \cdot B_{r 3 j}}{W_{r 1} \cdot Z_{r 1 j}} \\
\theta_{12}(j)= & \left(W_{r 6} \cdot C_{r 6 j}+W_{r 7} \cdot D_{r 7 j}+W_{r 8} \cdot E_{r 8 j}\right. \\
& \left.+W_{r 9} \cdot G_{r 9 j}+W_{r 10} \cdot Z_{r 10 j}\right) \\
& \cdot\left(W_{r 4} \cdot Z_{r 4 j}+W_{r 5} \cdot F_{r 5 j}\right)^{-1}
\end{aligned}
$$

$$
\begin{aligned}
& \theta_{13}(j)=\frac{W_{r 11} \cdot Z_{r 11 j}}{W_{r 10} \cdot Z_{r 10 j}} \\
& \theta_{14}(j)=\frac{W_{r 5} \cdot F_{r 5 j}+W_{r 13} \cdot X_{r 13 j}}{W_{r 11} \cdot Z_{r 11 j}+W_{r 9} \cdot G_{r 9 j}} .
\end{aligned}
$$

For activities of Process 2,

$\theta_{21}(j)=\frac{W_{r 15} \cdot Z_{r 15 j}}{W_{r 13} \cdot X_{r 13 j}}$

$\theta_{22}(j)=\frac{W_{r 17} \cdot Z_{r 17 j}+W_{r 16} \cdot M_{r 16 j}}{W_{r 15} \cdot Z_{r 15 j}+W_{r 14} \cdot H_{r 14 j}+W_{r 6} \cdot C_{r 6 j}}$ 


$$
\begin{aligned}
\theta_{23}(j)= & \frac{W_{r 18} \cdot Z_{r 18 j}}{W_{r 17} \cdot Z_{r 17 j}+W_{r 2} \cdot A_{r 2 j}+W_{r 7} \cdot D_{r 7 j}} \\
\theta_{24}(j)= & \left(W_{r 14} \cdot H_{r 14 j}+W_{r 19 j} \cdot Y_{r 19 j}\right) \\
& \cdot\left(W_{r 8} \cdot E_{r 8 j}+W_{r 18} \cdot Z_{r 18 j}\right. \\
& \left.+W_{r 16} \cdot M_{r 16 j}+W_{r 3} \cdot B_{r 3 j}\right)^{-1} .
\end{aligned}
$$

Each period is a process in the second level. The efficiency of each process is measured by the following.

For Process 1,

$$
\begin{aligned}
\theta_{t 1}(j)= & \left(W_{r 13} \cdot X_{r 13 j}+W_{r 2} \cdot A_{r 2 j}+W_{r 3} \cdot B_{r 3 j}\right. \\
& \left.+W_{r 6} \cdot C_{r 6 j}+W_{r 7} \cdot D_{r 7 j}+W_{r 8} \cdot E_{r 8 j}\right) \\
& \cdot\left(W_{r 1} \cdot X_{r 1 j}\right)^{-1} .
\end{aligned}
$$

For Process 2,

$$
\begin{aligned}
\theta_{t 2}(j)= & \left(W_{r 19} \cdot Y_{r 19 j}\right) \\
& \cdot\left(W_{r 13} \cdot X_{r 13 j}+W_{r 2} \cdot A_{r 2 j}+W_{r 3} \cdot B_{r 3 j}\right. \\
& \left.+W_{r 6} \cdot C_{r 6 j}+W_{r 7} \cdot D_{r 7 j}+W_{r 8} \cdot E_{r 8 j}\right)^{-1} .
\end{aligned}
$$

For the first level, the overall efficiency of system by considering the system as black box is measured by

$$
\theta_{T}(j)=\frac{W_{r 19} \cdot Y_{r 19 j}}{W_{r 1} \cdot X_{r 1 j}}
$$

The black-box approach in the DEA was originally developed to measure the efficiency of a DMU as a whole unit by ignoring internal relationships. The calculated efficiency with this approach may not be true because the operations of the component processes are ignored [34]. It may overestimate the efficiency of ignoring the intermediate input/output measures [45]. The black-box objective function is the simplest approach that comes to mind for a dynamic network in the Figure 5. But because it ignores the operations of the component processes and activities in second and third level, it is not an appropriate approach. Hence, for considering the network and dynamic operations of the component in a sublevel, the additive model based on Chen et al. [30] is used.

The weighted average of the efficiencies of the individual components in the activity level treated as perspectives of the dynamic BSC is measured by

$$
\beta_{p}=\frac{\text { (component } p \text { input) }}{\text { (total input accross all components) }} .
$$

For example the weight of first activity in first period is modeled by

$$
\begin{aligned}
\beta_{11}= & \left(W_{r 1} \cdot X_{r 1 j}\right) \\
& \cdot\left(W_{r 1} \cdot X_{r 1 j}+W_{r 4} Z_{r 4 j}+W_{r 5} \cdot F_{r 5 j}\right. \\
& \left.+W_{r 10} \cdot Z_{r 10 j}+W_{r 11} \cdot Z_{r 11 j}+W_{r 9} \cdot G_{r 9 j}\right)^{-1} .
\end{aligned}
$$

Similarly, for the other activities the weights are calculated. The above coefficients are the weights of perspectives of the BSC in the third level named activities. The weights of each period in the second level, named processes, are measured as follows.

For Process 1,

$$
\begin{aligned}
\beta_{t 1}= & \left(W_{r 1} \cdot X_{r 1 j}\right) \\
& \cdot\left(W_{r 1} \cdot X_{r 1 j}+W_{r 13} \cdot X_{r 13 j}+W_{r 2} \cdot A_{r 2 j}\right. \\
& +W_{r 3} \cdot B_{r 3 j}+W_{r 6} \cdot C_{r 6 j} \\
& \left.+W_{r 7} \cdot D_{r 7 j}+W_{r 8} \cdot E_{r 8 j}\right)^{-1} .
\end{aligned}
$$

For Process 2,

$$
\begin{aligned}
\beta_{t 2}=( & W_{r 13} \cdot X_{r 13 j}+W_{r 2} \cdot A_{r 2 j}+W_{r 3} \cdot B_{r 3 j} \\
& \left.+W_{r 6} \cdot C_{r 6 j}+W_{r 7} \cdot D_{r 7 j}+W_{r 8} \cdot E_{r 8 j}\right) \\
& \left(W_{r 1} \cdot X_{r 1 j}+W_{r 13} \cdot X_{r 13 j}+W_{r 2} \cdot A_{r 2 j}\right. \\
& +W_{r 3} \cdot B_{r 3 j}+W_{r 6} \cdot C_{r 6 j} \\
& \left.+W_{r 7} \cdot D_{r 7 j}+W_{r 8} \cdot E_{r 8 j}\right)^{-1} .
\end{aligned}
$$

In the studies carried out so far in the network DEA model, the weighted average of processes is considered as objective function. In the structure of this paper in Figure 5, the third level with network relationships is added. Then, the classic weighted average of processes as objective function is not appropriate and needs to be defined as a new objective function. Considering a network relationship in the third level between activities, the weighted average of activities in each process in the third level measure is considered for measuring the weighted average of the process in the second level as follows:

$$
\begin{aligned}
\operatorname{Max} \theta: & \beta_{t 1} \cdot\left(\beta_{11} \cdot \theta_{11}+\beta_{12} \cdot \theta_{12}+\beta_{13} \cdot \theta_{13}+\beta_{14} \cdot \theta_{14}\right) \\
& +\beta_{t 2} \cdot\left(\beta_{21} \cdot \theta_{21}+\beta_{22} \cdot \theta_{22}+\beta_{23} \cdot \theta_{23}+\beta_{24} \cdot \theta_{24}\right) .
\end{aligned}
$$

In (18), the processes efficiency is a convex combination of activities efficiency and the system efficiency is a convex combination of the processes efficiency because

$$
\begin{gathered}
\beta_{11}+\beta_{12}+\beta_{13}+\beta_{14}=1 \\
\beta_{21}+\beta_{22}+\beta_{23}+\beta_{24}=1 \\
\beta_{t 1}+\beta_{t 2}=1 .
\end{gathered}
$$


By adding constrains to the objective function of (18) based on Chen et al. [30], the model is completed.

Constrains of the third level are

$$
\begin{array}{ll}
\theta_{11} \leq 1 ; & \theta_{12} \leq 1 ; \\
\theta_{13} \leq 1 ; & \theta_{14} \leq 1 ; \\
\theta_{21} \leq 1 ; & \theta_{22} \leq 1 ; \\
\theta_{23} \leq 1 ; & \theta_{24} \leq 1 .
\end{array}
$$

Constrains of the second level are

$$
\theta_{t 1} \leq 1 ; \quad \theta_{t 2} \leq 1
$$

Constrain of the first level is

$$
\begin{gathered}
\theta_{T} \leq 1 \\
W_{r 1}, W_{r 2}, W_{r 3}, W_{r 4}, W_{r 5}, W_{r 6}, W_{r 7}, W_{r 8}, W_{r 9}, W_{r 10}, W_{r 11}, \\
W_{r 13}, W_{r 14}, W_{r 15}, W_{r 16}, W_{r 17}, W_{r 18}, W_{r 19} \geq 0 \\
j=1, \ldots, n .
\end{gathered}
$$

2.2.6. Measuring the Efficiency. To measure the efficiency based on the proposed model in the previous section, information of the KPIs of the NIORDC in Table 8 is used. The efficiency of nine refineries in three levels and the objective function of the model are illustrated in Table 9. By this calculation, the efficiency of each perspective and efficiency of each period and overall efficiency along with strategic goals and during the time are measured.

\section{Result and Discussion}

The integrated BSC and DEA model proposed in this paper to measure the efficiency during the time and along with strategic goals have been the main purpose. To follow this purpose, it should be understood how a time factor can be added to the cause-and-effect relation between perspectives of the BSC model. No study using the BSC and DEA models simultaneously has considered the time factor resulting from the lag KPIs as dynamic variables. In addition, no study has considered dynamics with attention to delay of the lag KPIs to draw the cause-and-effect relations of the BSC model reviewed so far. By deploying a proposed framework of this paper, the cause-and-effect relations of perspectives during the time with attention to delay of the lag KPIs between different periods and the lead KPIs in the same period have been created.

As shown in Figure 4, in addition to the classic relations from the "Learning and Growth" perspective to the "Financial" perspective, there are a recursive dynamic relation from the "Financial" perspective to "Internal processes" perspective and a circle loop relation from the "Internal processes" perspective to the "Financial" perspective in a period. There also are dynamic relationships as the dash lines

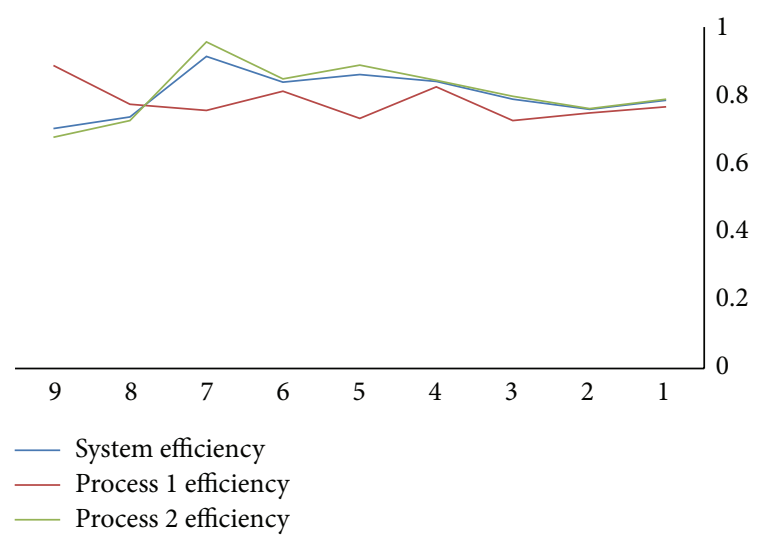

FIGURE 6: Efficiency score of nine refineries.

from perspectives of the first period to perspectives of the second period. Then, considering the time delay of the lag KPIs in different periods, the dynamic BSC and time factor are considered.

By considering a network relation of the dynamic BSC, the perspectives of each period and different periods have internal and external dynamic network relations, respectively. None of the network DEA structure reviewed so far does not consider the network relations in the third level and the relation of processes stages only is modeled. In the proposed network DEA structure, these relationships are considered.

By deploying the proposed framework, the efficiencies of each perspective and each period as well as the overall efficiency along with strategic goals and during the time considering delay of the lag KPIs are measured. As shown in Figure 6, the system efficiency is a convex combination of processes. It means that, for each DMU, the overall efficiency $(\theta)$ is between the maximum and minimum of each period efficiency $\left(\theta_{t 1}, \theta_{t 2}\right)$. The processes efficiency also is a convex combination of the activities efficiency. It also means that for each DMU, each period efficiency is between the maximum and minimum of perspectives efficiency. These convex relations indicate accuracy of the proposed formulation.

By considering Table 10, the 7th refinery has the best efficiency because of the good efficiency score in the "Financial" and "Internal processes" perspectives in the second period. The ninth refinery has the worth efficiency because of the bad efficiency score in the "customer" perspective in the second period. Similarly, for other refineries, the causes of good or bad efficiency scores are analyzed. Then, the root causes of these scores are cleared with attention to causal relations of perspectives. For example, considering the dynamic BSC as shown in Figure 3, the "Internal processes" perspective in the first period has causal relationships with the "Customer" perspective in the second period. Hence, the root cause of the bad efficiency score of 9th refinery is the bad performance of "Internal process." After identifying inefficient units, by considering the cause-and-effect relations of the dynamic BSC, the root cause of the bad efficiency scores is identified. Then, the strategic initiatives are revised to improve efficiency 
TABLE 10: Calculated efficiency of nine refineries of NIORDC in three levels.

\begin{tabular}{lccccccccccc}
\hline & System & \multicolumn{2}{c}{ Processes } & \multicolumn{3}{c}{ Activity of period 1 } & \multicolumn{4}{c}{ Activity of period 2 } \\
& $\theta$ & $\theta_{t 1}$ & $\theta_{t 2}$ & $\theta_{13}$ & $\theta_{14}$ & $\theta_{13}$ & $\theta_{14}$ & $\theta_{21}$ & $\theta_{22}$ & $\theta_{23}$ & $\theta_{24}$ \\
\hline DMU1 & 0.786 & 0.766 & 0.789 & 0.624 & 1 & 0.553 & 0.727 & 0.7 & 0.762 & 0.705 & 0.879 \\
DMU2 & 0.759 & 0.748 & 0.761 & 0.561 & 0.998 & 0.574 & 0.731 & 0.699 & 0.89 & 0.719 & 0.717 \\
DMU3 & 0.789 & 0.726 & 0.797 & 1 & 0.628 & 0.565 & 0.78 & 0.683 & 0.976 & 0.721 & 0.76 \\
DMU4 & 0.841 & 0.825 & 0.844 & 0.728 & 0.892 & 0.436 & 1 & 0.597 & 0.766 & 0.756 \\
DMU5 & 0.861 & 0.733 & 0.888 & 0.586 & 1 & 0.414 & 0.756 & 1 & 1 & 0.625 \\
DMU6 & 0.839 & 0.812 & 0.848 & 0.504 & 0.924 & 0.523 & 1 & 0.483 & 0.703 & 1 \\
DMU7 & 0.914 & 0.756 & 0.956 & 0.688 & 1 & 0.496 & 0.72 & 0.642 & 1 & 0.902 \\
DMU8 & 0.737 & 0.774 & 0.726 & 0.29 & 0.924 & 0.462 & 1 & 0.505 & 1 & 0.918 & 0.414 \\
DMU9 & 0.703 & 0.887 & 0.677 & 0.609 & 0.968 & 1 & 0.94 & 0.621 & 0.897 & 0.331 & 0.703 \\
\hline
\end{tabular}

scores. This also is a good method for making a decision on which improvement projects should be started or revised.

\section{Conclusion}

In this paper, the time factor has been considered with severance of the lead and lag KPIs for drawing the casual relationships during the time with the fuzzy DEMATEL model. By considering the network relations of the dynamic BSC, a new two-stage DEA structure with three levels has been proposed. For formulation of this structure, the weighted average of activities efficiency (i.e., efficiency of perspectives) in the third level has produced weights of the processes efficiency (i.e., weights of periods) as objective function. Then, dynamic and nondynamic variables based on the lag and lead KPIs have been considered, respectively, for the efficiency measurement. In this new objective function, the dynamic network relations of the third level among perspectives have been considered for measuring the efficiency, and the weakness of ignoring these relations have been removed. Based on the proposed framework, the efficiency of nine subsidiary refineries of the NIORDC during the time and along with strategic goals has been measured. By reporting the relationship of the dynamic BSC and these efficiency scores to the NIORDC managers, the results of the proposed framework have been confirmed and validated in experimental space. It can be interesting to use time series based methods (e.g., REF-II model) to predict the efficiency score of DMUs with the data set of the last KPIs for future research.

\section{Conflict of Interests}

The authors declare that there is no conflict of interests regarding the publication of this paper.

\section{Acknowledgments}

The authors would like to thank anonymous reviewers for their valuable comments. Additionally, the authors thank the National Iranian Oil Refining \& Distribution Company for providing the real data.

\section{References}

[1] R. S. Kaplan and D. P. Norton, "Using the balanced scorecard as a strategic management system," Harvard Business Review, vol. 74, no. 2, pp. 70-82, 1996.

[2] V. Nissen, "Modeling corporate strategy with the fuzzy balanced scorecard," in Proceedings of the Symposium on Fuzzy Systems in Computer Science (FSCS '06), E. Hüllermeier, R. Kruse, A. Nürnberger, and J. Strackeljan, Eds., pp. 121-138, Magdeburg, Germany, 2006.

[3] R. S. Kaplan and D. P. Norton, "The strategy map: guide to aligning intangible assets," Strategy \& Leadership, vol. 32, no. 5, pp. 10-17, 2004.

[4] M. L. Frigo, P. G. Pustorino, and G. W. Krull, "The balanced scorecard for community banks: translating strategy into action," Bank Accounting and Finance, vol. 13, no. 3, pp. 17-29, 2000.

[5] P. Rouse, M. Putterill, and D. Ryan, "Integrated performance measurement design: insights from an application in aircraft maintenance," Management Accounting Research, vol. 13, no. 2, pp. 229-248, 2002.

[6] H. Eilat, B. Golany, and A. Shtub, "R\&D project evaluation: an integrated DEA and balanced scorecard approach," Omega, vol. 36, no. 5, pp. 895-912, 2008.

[7] H. Eilat, B. Golany, and A. Shtub, "Constructing and evaluating balanced portfolios of R\&D projects with interactions: a DEA based methodology," European Journal of Operational Research, vol. 172, no. 3, pp. 1018-1039, 2006.

[8] T.-Y. Chen, C.-B. Chen, and S.-Y. Peng, "Firm operation performance analysis using data envelopment analysis and balanced scorecard: a case study of a credit cooperative bank," International Journal of Productivity and Performance Management, vol. 57, no. 7, pp. 523-539, 2008.

[9] T. García-Valderrama, E. Mulero-Mendigorri, and D. RevueltaBordoy, "Relating the perspectives of the balanced scorecard for R\&D by means of DEA," European Journal of Operational Research, vol. 196, no. 3, pp. 1177-1189, 2009.

[10] C. Y. Chiang and B. Lin, "An integration of balanced scorecards and data envelopment analysis for firm's benchmarking management," Total Quality Management and Business Excellence, vol. 20, no. 11, pp. 1153-1172, 2009.

[11] M. A. Maced, A. C. Barbosa, and G. T. Cavalcante, "Performance of bank branches in Brazil: applying data envelopment analysis (DEA) to indicators related to the BSC perspectives," E¿ G-Revista Economia e Gestão, vol. 19, no. 19, pp. 65-84, 2009. 
[12] A. Asosheh, S. Nalchigar, and M. Jamporazmey, "Information technology project evaluation: an integrated data envelopment analysis and balanced scorecard approach," Expert Systems with Applications, vol. 37, no. 8, pp. 5931-5938, 2010.

[13] C. A. F. Amado, S. P. Santos, and P. M. Marques, "Integrating the data envelopment analysis and the balanced scorecard approaches for enhanced performance assessment," Omega, vol. 40, no. 3, pp. 390-403, 2012.

[14] S. M. Seyedhosseini, A. E. Taleghani, A. Bakhsha, and S. Partovi, "Extracting leanness criteria by employing the concept of balanced scorecard," Expert Systems with Applications, vol. 38, no. 8, pp. 10454-10461, 2011.

[15] E. Falatoonitoosi, Z. Leman, and S. Sorooshian, "Casual strategy mapping using integrated BSC and MCDM DEMATEL," Journal of American Science, vol. 8, no. 1, pp. 125-155, 2012.

[16] J.-S. Horng, C.-H. Liu, S.-F. Chou, and C.-Y. Tsai, "Creativity as a critical criterion for future restaurant space design: developing a novel model with DEMATEL application," International Journal of Hospitality Management, vol. 33, no. 1, pp. 96-105, 2013.

[17] M. N. Shaik and W. Abdul-Kader, "Comprehensive performance measurement and causal-effect decision making model for reverse logistics enterprise," Computers and Industrial Engineering, vol. 68, no. 1, pp. 87-103, 2014.

[18] J. Jassbi, F. Mohamadnejad, and H. Nasrollahzadeh, "A fuzzy DEMATEL framework for modeling cause and effect relationships of strategy map," Expert Systems with Applications, vol. 38, no. 5, pp. 5967-5973, 2011.

[19] S. A. Heydariyeh, M. Javidnia, and A. Mehdiabadi, "A new approach to analyze strategy map using an integrated BSC and FUZZY DEMATEL," Management Science Letters, vol. 2, no. 1, pp. 161-170, 2012.

[20] C. Chen and H. Yan, "Network DEA model for supply chain performance evaluation," European Journal of Operational Research, vol. 213, no. 1, pp. 147-155, 2011.

[21] M. Alvandi, S. Fazli, L. Yazdani, and M. Aghaee, "An integrated MCDM method in ranking BSC perspectives and key performance indicators (KPIs)," Management Science Letters, vol. 2, no. 3, pp. 995-1004, 2012.

[22] D. J.-F. Jeng and G.-H. Tzeng, "Social influence on the use of clinical decision support systems: revisiting the unified theory of acceptance and use of technology by the fuzzy DEMATEL technique," Computers and Industrial Engineering, vol. 62, no. 3, pp. 819-828, 2012.

[23] J. Ren, A. Manzardo, S. Toniolo, and A. Scipioni, "Sustainability of hydrogen supply chain. Part I: identification of critical criteria and cause-effect analysis for enhancing the sustainability using DEMATEL," International Journal of Hydrogen Energy, vol. 38, no. 33, pp. 14159-14171, 2013.

[24] J. S. Horng, C. H. Liu, S. F. Chou, and C. Y. Tsai, "Creativity as a critical criterion for future restaurant space design: developing a novel model with DEMATEL application," International Journal of Hospitality Management, vol. 33, no. 1, pp. 96-105, 2013.

[25] C. Kao, "Network data envelopment analysis: a review," European Journal of Operational Research, vol. 239, no. 1, pp. 1-16, 2014.

[26] L. M. Seiford and J. Zhu, "Profitability and marketability of the top 55 U.S. commercial banks," Management Science, vol. 45, no. 9, pp. 1270-1288, 1999.

[27] Z. Yang, "A two-stage DEA model to evaluate the overall performance of Canadian life and health insurance companies," Mathematical and Computer Modelling, vol. 43, no. 7-8, pp. 910919, 2006.
[28] C. Kao and S.-N. Hwang, "Efficiency decomposition in twostage data envelopment analysis: an application to non-life insurance companies in Taiwan," European Journal of Operational Research, vol. 185, no. 1, pp. 418-429, 2008.

[29] Y.-C. Chiou, L. W. Lan, and B. T. H. Yen, "A joint measurement of efficiency and effectiveness for non-storable commodities: integrated data envelopment analysis approaches," European Journal of Operational Research, vol. 201, no. 2, pp. 477-489, 2010.

[30] Y. Chen, W. D. Cook, and J. Zhu, "Deriving the DEA frontier for two-stage processes," European Journal of Operational Research, vol. 202, no. 1, pp. 138-142, 2010.

[31] Y.-M. Wang and K.-S. Chin, "Some alternative DEA models for two-stage process," Expert Systems with Applications, vol. 37, no. 12, pp. 8799-8808, 2010.

[32] C. Kao and S.-N. Hwang, "Decomposition of technical and scale efficiencies in two-stage production systems," European Journal of Operational Research, vol. 211, no. 3, pp. 515-519, 2011.

[33] H. F. Lewis, S. Mallikarjun, and T. R. Sexton, "Unoriented twostage DEA: the case of the oscillating intermediate products," European Journal of Operational Research, vol. 229, no. 2, pp. 529-539, 2013.

[34] A. Charnes, W. W. Cooper, B. Golany, R. Halek, G. Klopp, and E. Schmitz, "Two-phase data envelopment analysis approaches to policy evaluation and management of army recruiting activities: tradeoffs between joint services and army advertising," Research Report CCS \#532, Center for Cybernetic Studies. University of Texas-Austin, Austin, Tex, USA, 1986.

[35] C. Kao and S.-N. Hwang, "Efficiency measurement for network systems: IT impact on firm performance," Decision Support Systems, vol. 48, no. 3, pp. 437-446, 2010.

[36] Y. Chen, J. Du, H. D. Sherman, and J. Zhu, "DEA model with shared resources and efficiency decomposition," European Journal of Operational Research, vol. 207, no. 1, pp. 339-349, 2010.

[37] L. Liang, Z.-Q. Li, W. D. Cook, and J. Zhu, "Data envelopment analysis efficiency in two-stage networks with feedback," IIE Transactions, vol. 43, no. 5, pp. 309-322, 2011.

[38] B. C. Xie, Y. Fan, and Q. Q. Qu, "Does generation form influence environmental efficiency performance? An analysis of China's power system," Applied Energy, vol. 96, pp. 261-271, 2012.

[39] S. Lozano, E. Gutiérrez, and P. Moreno, "Network DEA approach to airports performance assessment considering undesirable outputs," Applied Mathematical Modelling, vol. 37, no. 4, pp. 1665-1676, 2013.

[40] J. Nouri, F. H. Lotfi, H. Borgheipour, F. Atabi, S. M. Sadeghzadeh, and Z. Moghaddas, "An analysis of the implementation of energy efficiency measures in the vegetable oil industry of Iran: a data envelopment analysis approach," Journal of Cleaner Production, vol. 52, pp. 84-93, 2013.

[41] C. Kao and S.-T. Liu, "Multi-period efficiency measurement in data envelopment analysis: the case of Taiwanese commercial banks," Omega, vol. 47, pp. 90-98, 2014.

[42] C. Kao, "Efficiency measurement for parallel production systems," European Journal of Operational Research, vol. 196, no. 3, pp. 1107-1112, 2009.

[43] G. Bi, C. Feng, J. Ding, and M. R. Khan, "Estimating relative efficiency of DMU: Pareto principle and Monte Carlo oriented DEA approach," Information Systems and Operational Research, vol. 50, no. 1, pp. 44-57, 2012. 
[44] N. Adler, V. Liebert, and E. Yazhemsky, "Benchmarking airports from a managerial perspective," Omega, vol. 41, no. 2, pp. 442458, 2013.

[45] C.-H. Wang, Y.-H. Lu, C.-W. Huang, and J.-Y. Lee, "R\&D, productivity, and market value: an empirical study from hightechnology firms," Omega, vol. 41, no. 1, pp. 143-155, 2013.

[46] T.-Y. Lin and S.-H. Chiu, "Using independent component analysis and network DEA to improve bank performance evaluation," Economic Modelling, vol. 32, no. 1, pp. 608-616, 2013.

[47] G. Klepac, "Risk evaluation in the insurance company using REFII model," Intelligent techniques in recommendation systems: contextual advancements and new methods, pp. 84-104, 2012.

[48] C. L. Lin and W. W. Wu, "A fuzzy extension of the DEMATEL method for group decision making," European Journal of Operational Research, vol. 156, Article ID 445455, pp. 445-455, 2004.

[49] W.-S. Lee, A. Y. Huang, Y.-Y. Chang, and C.-M. Cheng, "Analysis of decision making factors for equity investment by DEMATEL and analytic network process," Expert Systems with Applications, vol. 38, no. 7, pp. 8375-8383, 2011. 


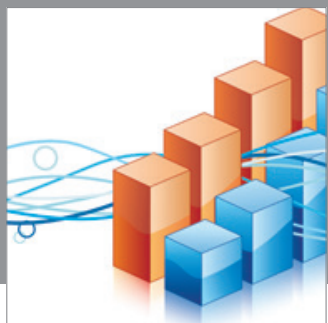

Advances in

Operations Research

mansans

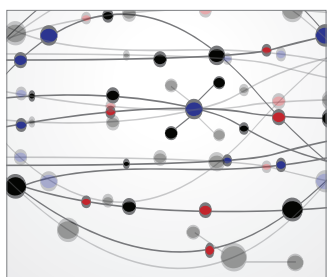

The Scientific World Journal
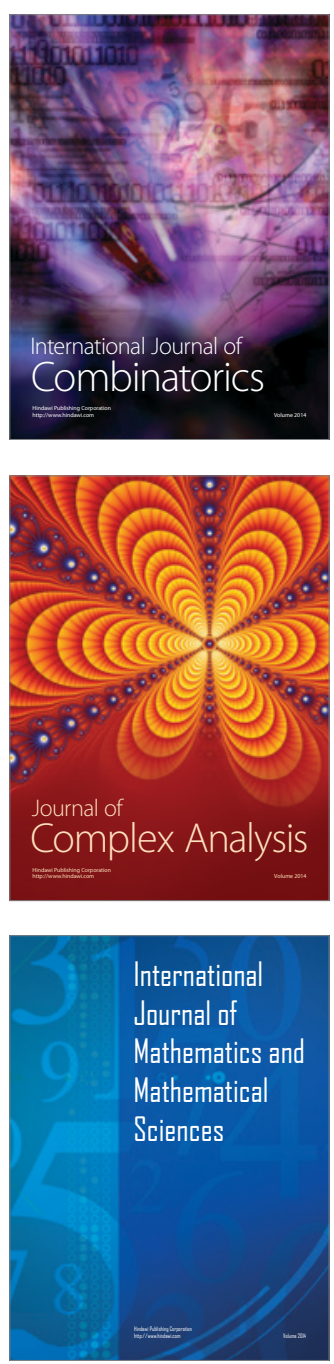
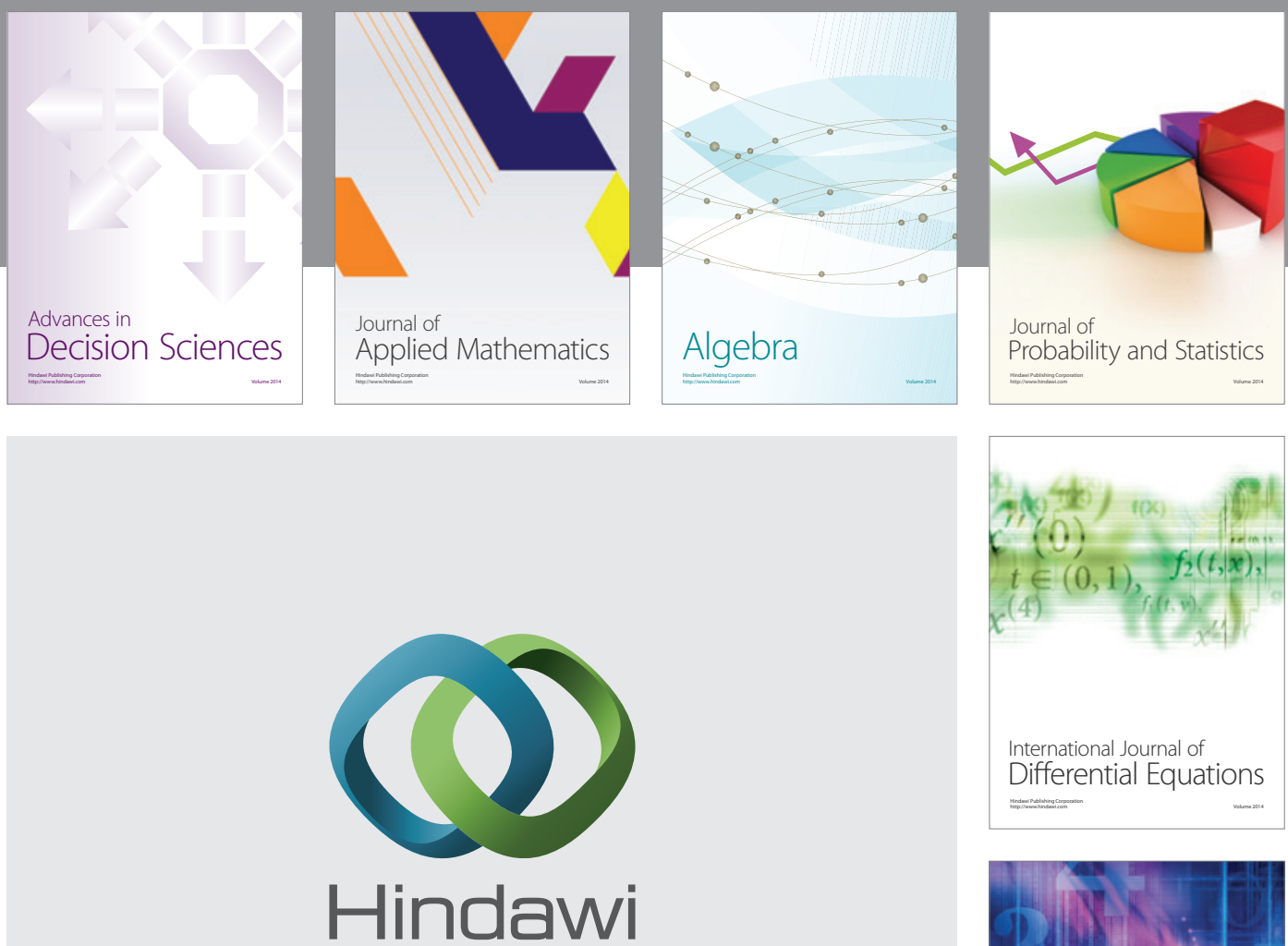

Submit your manuscripts at http://www.hindawi.com
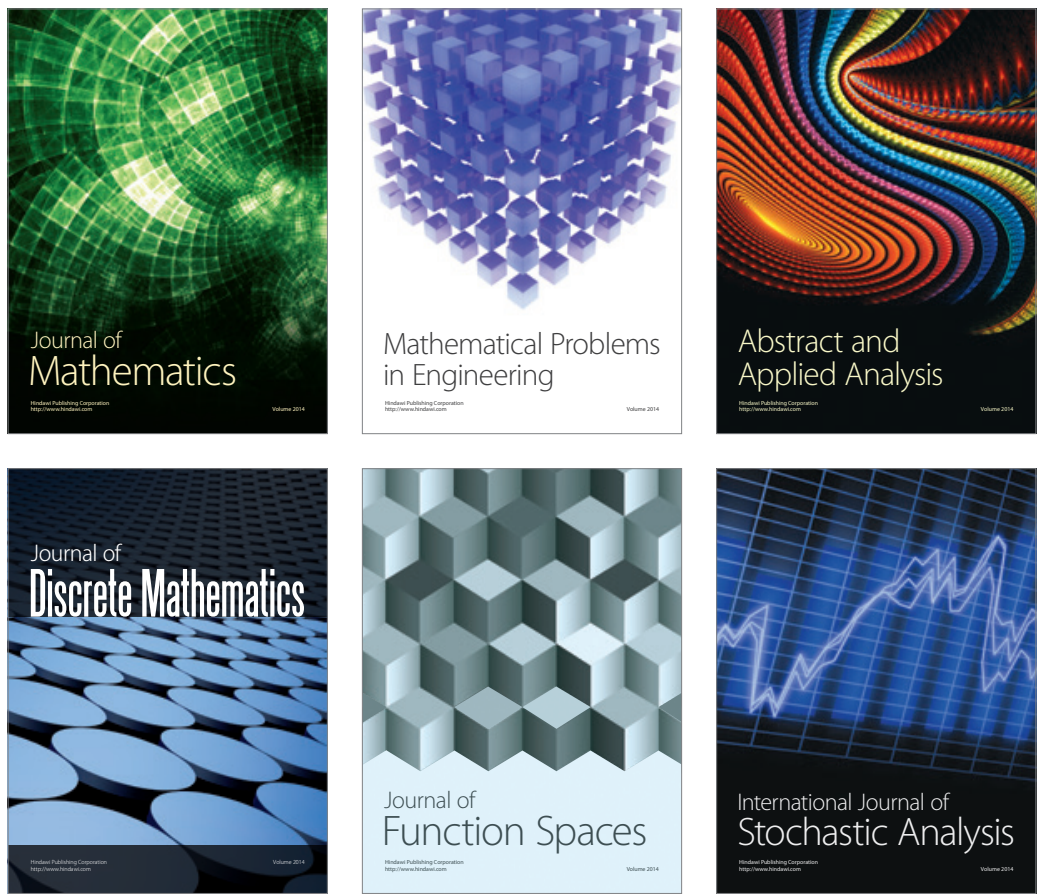

Journal of

Function Spaces

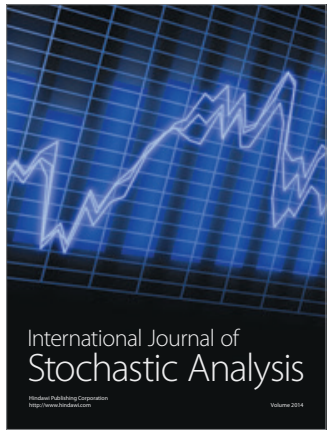

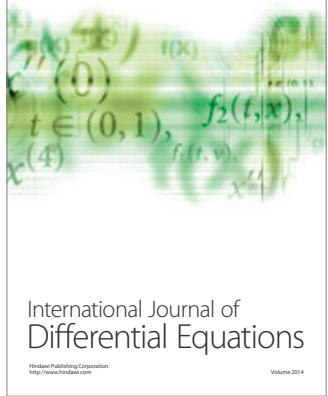
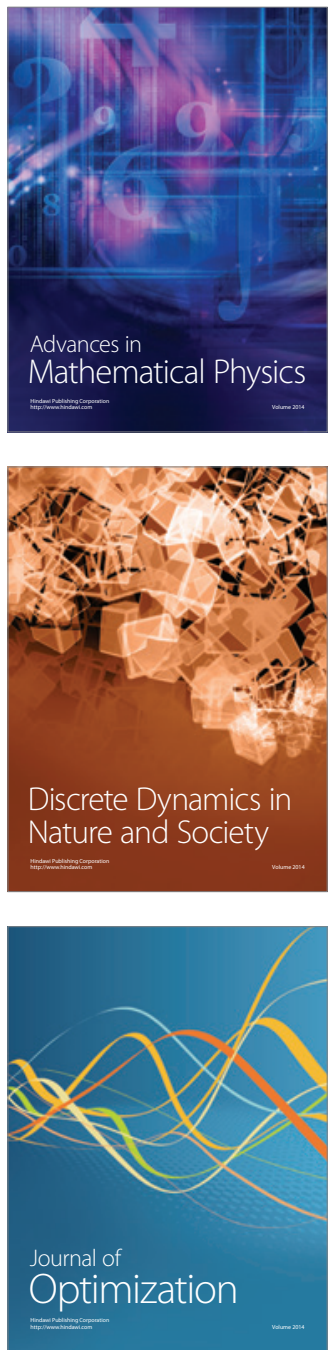